\title{
Infrequent detection of Chlamydia trachomatis in a longitudinal study of women with treated cervical infection
}

\author{
P E Munday, B J Thomas, C B Gilroy, C Gilchrist, D Taylor-Robinson
}

\begin{abstract}
Objective-To determine how often Chlamydia trachomatis cervical infections are detected in women following completion of a currently recommended treatment regimen and the reason for recurrence.

Methods-A longitudinal follow-up study of 43 initially $C$ trachomatis-positive women for periods of up to two years.

Results-C trachomatis was detected in three women, 19, 16 and about four months, respectively after completion of treatment. All specimens from the other 40 women which were taken during visits two to seven, that is periods of three to 700 days after treatment, were chlamydia-negative.

Conclusion-Although $C$ trachomatis is usually eradicated from the genital tract by conventional treatment, occasionally it may be found again. It is difficult to determine whether detection after treatment is due to persistence or reinfection and further studies are required.
\end{abstract}

(Genitourin Med 1995;71:24-26)

Keywords: Chlamydia; Recurrence

\section{Introduction}

Lower genital tract chlamydial infection in women may lead to serious sequelae, namely pelvic inflammatory disease, ectopic pregnancy, tubal infertility and chronic pelvic pain. Conventionally, uncomplicated infection is treated with short courses of antibiotics, usually tetracyclines or macrolides, which result apparently in very high cure rates. ${ }^{1-3}$ Treatment failure is attributed usually to reinfection. ${ }^{4}$ Furthermore, development of resistance in vitro to antibiotics has not been recorded, with the exception of that to rifampicin, ${ }^{5}$ and in many settings it is felt inappropriate to test for cure. ${ }^{6}$ However, despite this, it is possible that chlamydiae may sometimes not be eradicated but may persist in small numbers in an inactive ("latent") state and go undetected by cultural and immunoassay methods, a situation which occurs in another chlamydial disease, trachoma. ${ }^{7}$ If this were the case, activation and shedding of the organisms might occur from time to time, so that some women would be at continuing risk of developing pelvic inflammatory disease and of infecting sexual partners following treatment. In most studies, follow-up periods have been very short ${ }^{1-4}$ and it is well recognised that long term follow-up is difficult because of the mobility of patients and the problem of distinguishing relapse from reinfection.

In this study, we used the most sensitive chlamydial detection techniques currently available to examine endocervical specimens from women. They were seen repeatedly up to two years after they had been treated conventionally for uncomplicated chlamydial infection, the aim being to determine whether chlamydiae could be detected again and, if so, the possible reason.

\section{Patients and methods}

The study was approved by the hospital ethics committee and all participants gave written informed consent. Unselected women with an uncomplicated chlamydial cervical infection, attending the Department of Genitourinary Medicine at Watford General Hospital, were treated with a seven day course of triple tetracycline (chlortetracycline hydrochloride $115 \cdot 4$ $\mathrm{mg}$, tetracycline hydrochloride $115.4 \mathrm{mg}$ and demeclocycline hydrochloride $69.2 \mathrm{mg}$; Deteclo, Lederle). Then they were followed up by screening for infection at $3,21,90,180$ and 365 days after completion of treatment. Opportunistic testing was also carried out during and up to a year after the study period in those women who failed to keep to the protocol.

At each visit, endocervical specimens were taken for detection of $C$ trachomatis elementary bodies by a direct fluorescence antibody (DFA) test (MicroTrak; Syva, UK) ${ }^{8}$ For those patients who were $C$ trachomatis-positive at a subsequent visit, duplicate specimens from both visits were smeared on slides for serotyping by using specific monoclonal antibodies (Washington Research Foundation) in an indirect fluorescence test. In one case in which there were insufficient elementary bodies, a duplicate specimen stored in liquid nitrogen was cultured by using cycloheximide-treated $\mathrm{McCoy}$ cells ${ }^{9}$ and the organisms serotyped by the method mentioned above. At the last visit, an additional specimen was taken to be tested by means of an "in-house" polymerase chain reaction (PCR). ${ }^{10}$ Some opportunistic testing was carried out with the enzyme immunoassay (EIA) technique in use in the Department of Genitourinary Medicine at the time (initially Chlamydiazyme (Abbott) but subsequently the Syva test).

Sexual partners were invited to attend; they were screened using the DFA test and routine 
Table 1 Clinical and microbiological findings in Case 1

16 May $1990 \quad \mathrm{Ct}^{\star}$-positive by DFAt; serovar $\mathrm{E}$

3-20 June 1990 Treated with a tetracycline

21 June 1990 Partner examined; Ct-negative; no urethritis

28 June 1990 Ct-negative by DFA

26 July $1990 \quad$ Ct-negative by DFA

31 October 1990 Ct-negative by DFA

January 1991 Started new relationship

January 1992 Ct-positive by DFA and PCR $\neq$; serovar E

June 1992

*Chlamydia trachomatis.

†MicroTrak test.

$\ddagger$ Polymerase chain reaction.

tests were undertaken. If there was evidence of urethritis or $C$ trachomatis was identified, a course of appropriate treatment was prescribed. In some cases, the attendance of the partner had preceded that of the patient and then it was not possible to obtain additional specimens from him.

At each visit, a history was taken of intercurrent antibiotic therapy and details of any new sexual partners. Women were excluded if they were pregnant or failed to attend for any follow-up examinations. If a participant subsequently took a course of antibiotics active against chlamydiae she was excluded from the analysis.

\section{Results}

Fifty-five $C$ trachomatis-positive women were enrolled in the study but 12 were excluded from the analysis for the following reasons: pregnancy (one case), failure to return for any follow-up examinations (seven cases), or additional antibiotic therapy received before the first follow-up examination (four cases).

Of the 43 patients who were followed up for at least one post-treatment examination, three were found to be chlamydia-positive subsequently. One patient was chlamydiapositive on day 605 as determined by both DFA and PCR tests and the organisms were typed as serovar E, the same serovar as identified in her index infection. Details of her follow-up tests are shown in table 1 . The second patient (table 2) was chlamydia-positive on day 486 as shown by the PCR assay only. However, culture of a duplicate stored specimen confirmed the presence of $C$ trachomatis which was typed as serovar E, the same serovar as detected initially. The third patient was chlamydia-positive by an EIA on day 114, but it was not possible to obtain specimens

Table 2 Clinical and microbiological findings in Case 2

\begin{tabular}{|c|c|}
\hline 5 October 1990 & $\begin{array}{l}\text { Partner: non-gonococcal urethritis, Ct* } t^{\star} \text {-positive by DFAt; } \\
\text { treated with triple tetracycline }(5 \text { to } 19 \cdot 10 \cdot 90)\end{array}$ \\
\hline $\begin{array}{l}8 \text { October } 1990 \\
8-15 \text { October } 1990 \\
19 \text { November } 1990 \\
1 \text { February } 1991 \\
4 \text { February } 1992\end{array}$ & $\begin{array}{l}\text { Patient asymptomatic; Ct-positive by DFA (serovar E } \pm \mathrm{G} \text { ) } \\
\text { Treated with triple tetracycline } \\
\text { Ct-negative by DFA } \\
\text { Ct-negative by DFA } \\
\text { Asymptomatic apart from long-standing vulval } \\
\text { itching; Ct-positive by PCR } ¥ \text { (culture and serotyping } \\
\text { confirmed serovar E) } \\
\text { Same regular partner. }\end{array}$ \\
\hline
\end{tabular}

^Chlamydia trachomatis.

†MicroTrak test.

$\ddagger$ Polymerase chain reaction. from her partner who attended another clinic. The other 40 patients were followed up for periods of between four and 700 days (mean 161 days; median 93 days) and the results of DFA and/or EIA tests for $C$ trachomatis on one to six occasions were negative. Specimens from nine of these patients (duration of follow up: mean 232 days; median 242 days; range 85-412 days) were examined at their last visit by means of the PCR assay; all of them were negative.

\section{Discussion}

The results of previous studies have suggested that persistent infection following appropriate antibiotic therapy for $C$ trachomatis is rare. Most studies have had relatively short followup periods and positive tests for chlamydiae after treatment have usually been attributed to reinfection. This undoubtedly happens when sexual intercourse is resumed with an untreated partner. It is, however, more difficult to be so adamant about reinfection when a new relationship has been established, as it would be necessary to assume that the new partner was also infected with chlamydiae. In the first case in which chlamydiae were detected a second time, the long interval between the original infection and the finding of chlamydiae again, together with their detection so soon after the establishment of a new relationship, suggest reinfection (a new infection). However, the existence in the second infection of the same and most common serovar, namely $E$, as in the first raises the possibility of persistence and relapse. Clearly, serotyping in this case has not helped in resolving the dilemma.

In the second case, as in the first, the patient became chlamydia-positive with the same serovar after a long interval. However, the situation was different in that the relationship was stable, and detailed questioning of both partners separately failed to identify a possible source of a new infection. Of course, a new infection cannot be ruled out absolutely, but the sequence of events suggests that one or other partner may have had a persistent infection following the original treatment.

In the third case, the patient was known to have had several partners after being treated for her chlamydial infection and before becoming chlamydia-positive again, but specimens were not available from her current partner. Acquisition of a new infection seemed likely, but supportive evidence was not available.

The three cases illustrate the difficulty of assuring whether the detection of chlamydiae after treatment is due to persistence and relapse or to reinfection. Progress in this area might be made as follows. $C$ trachomatis could be serotyped by the method we have used or by a PCR-based method, preferably directly on non-cultured specimens. ${ }^{11}$ Detection of a different serovar after an interval would indicate reinfection, whereas detection of the same serovar would not distinguish between reinfection and relapse. To do this requires 
the ability to differentiate between strains within a serovar at the molecular level which should become feasible in the future. If the same strain were to be identified after an interval this would indicate relapse rather than reinfection, assuming that there are a number of different strains within a serovar.

When trachoma is clinically inactive, antigen may be detected sometimes even in culture-negative cases, suggesting the presence of continuing infection. ${ }^{7}$ Although it is reasonable to draw analogies between genital-tract infection and trachoma, the results of previous studies of genital-tract infection have not provided evidence of continuing infection in the majority of cases. The results of the current study are consistent with this, the large majority of patients remaining chlamydia-negative after prolonged periods of observation even when specimens were examined by the PCR assay, a technique regarded as perhaps the most sensitive currently available. ${ }^{12} \mathrm{~A}$ similar conclusion has been drawn by others. ${ }^{13}$ It seems likely, therefore, that chlamydiae do not persist frequently after conventional treatment, but if they do occasionally and are shed intermittently, the implications for the management of chlamydial infections are considerable. Tests of cure, which might have to be repeated on several occasions, are unlikely to be cost-effective and are not supported from this viewpoint by our data. However, it is important to collect further information on the frequency in stable relationships of persistent and recurrent chlamydial infection after treatment.
We thank the medical and nursing staff of the Department of Genitourinary Medicine at Watford General Hospital without whose support and co-operation this study could not have been conducted.

1 Bowie WR, Manzon LM, Borrie-Hume CJ, Fawcett A Jones HD. Efficacy of treatment regimens for lowe urogenital Chlamydia trachomatis infection in women. Am F Obstet Gynecol 1982;142:125-9.

2 Brunham RC, Kuo C-C, Stevens CE, Holmes KK Therapy of cervical chlamydial infection. Ann Intern Med 1982;97:216-9.

3 Waugh MA, Nayyar KC. Triple tetracycline (Deteclo) in the treatment of chlamydial infection of the female genital tract. $B r \mathcal{F}$ Venereal Dis 1977;53:96-7.

4 Oriel JD, Ridgway GL. Comparison of erythromycin and oxytetracycline in the treatment of cervical infection by Chlamydia trachomatis. $\mathcal{F}$ Infect 1980;2:259-62.

5 Keshishyan H, Hanna L, Jawetz E. Emergence of rifampinresistance in Chlamydia trachomatis. Nature 1973;244:173-4.

6 Radcliffe KW, Rowen D, Mercey D, et al. Is a test of cure necessary following treatment for cervical infection with
notcliffe $\mathrm{KW}$, Rowen $\mathrm{D}$, Mercey $\mathrm{D}$, et . Is a test of cure necessary following treatment for cervical infection with
Chlamydia trachomatis? Genitourin Med 1990;66:444-6.

7 Hanna L, Dawson CR, Briones O, Thygeson P, Jawetz E. Latency in human infections with TRIC agents. $\mathcal{f}$ Immunol 1968;101:43-50.

8 Thomas BJ, Evans RT, Hawkins DA, Taylor-Robinson D. Sensitivity of detecting Chlamydia trachomatis elementary bodies in smears by use of a fluorescein labelled monoclonal antibody: comparison with conventional chlamydial isolation. $\mathcal{F}$ Clin Pathol 1984;37:812-6.

9 Ripa KT, Mårdh P-A. Cultivation of Chlamydia trachomatis in cycloheximide-treated McCoy cells. $\mathcal{f}$ Clin Microbio 1977;6:328-31.

10 Palmer HM, Gilroy CB, Thomas BJ, Hay PE, Gilchrist C, Taylor-Robinson D. Detection of Chlamydia trachomatis by the polymerase chain reaction in swabs and urine by the polymerase chain reaction in swabs and urine
from men with non-gonococcal urethritis. $f$ Clin Pathol from men with

11 Lan J, Ossewaarde JM, Walboomers JMM, Meijer CJLM, van den Brule AJC. Improved PCR sensitivity for direct genotyping of Chlamydia trachomatis serovars by using nested PCR. F Clin Microbiol 1994;32:528-30.

2 Taylor-Robinson D, Thomas BJ. Laboratory techniques for the diagnosis of chlamydial infections. Genitourin Med 1991;67:256-66.

13 Workowski KA, Lampe MF, Wong KG, Watts MB, Stamm WE. Long-term eradication of Chlamydia trachomatis genital infection after antimicrobial therapy. Evidence against persistent infection. $\Im A M A$ 1993;270: 2071-5. 